\title{
Synthesis and Characterization of Graphene Oxide for the Adsorption of Cr(III) from Chrome-Tanning Effluent
}

Ahmed $\mathrm{S}^{1,3}$, Fatema-Tuj-Zohra ${ }^{1,3}$, Mahdi MM¹, Chowdhury TR², Md. Alam $\mathrm{Z}^{3}$, Md. Nurnabi ${ }^{3 *}$

${ }^{1}$ Institute of Leather Engineering and Technology, University of Dhaka, Bangladesh

${ }^{2}$ Analytical Chemistry Laboratory, Atomic Energy Center, Bangladesh Atomic Energy Commission, Dhaka, Bangladesh

${ }^{3}$ Department of Applied Chemistry and Chemical Engineering, University of Dhaka, Bangladesh

\section{Research Article}

Volume 5 Issue 1

Received Date: May 25, 2021

Published Date: June 28, 2021

DOI: $10.23880 / p s b j-16000177$

*Corresponding author: Md. Nurnabi, Department of Applied Chemistry and Chemical Engineering, University of Dhaka, Bangladesh, Tel: 01711112233; Email: azizahabdulhafiz@gmail.com

\section{Abstract}

Chromium released with tannery effluent causes severe water pollution which is a great concern to the environment and public health. The removal of chromium from tannery effluent before discharging to the surface water is a crying need for protecting environment and human health. This research work highlights the adsorption potential of graphene oxide (GO) for chromium(III) from hazardous chrome-tanning effluents. The research framework includes preparation and characterization of GO employing Field Emission Scanning Electron Microscopy (FESEM), X-ray diffraction (XRD) analysis, Zeta potential charge (ZPC), and Fourier Transform Infrared Spectroscopy (FTIR). Explanation of the adsorption mechanism, kinetics, and feasibility were also documented. The influence of different operational variables $\mathrm{pH}$, adsorbent dosage, $\mathrm{Cr}$ (III) ion concentration, contact time and temperature on adsorption were evaluated by batch experiments. The results demonstrated that the highest chromium removal $(98.77 \%$ ) was ascertained while treating chrome-tanning effluents $(174 \mathrm{mg} / \mathrm{L})$ with $0.6 \mathrm{~g} / \mathrm{L} \mathrm{GO}$ for 20 minutes at $\mathrm{pH}$ 4. The adsorption equilibrium followed both Langmuir and Freundlich isotherms with maximum adsorption capacity (qm) of $366.3 \mathrm{mg} / \mathrm{g}$. The adsorption kinetics was nicely interpreted with a pseudo-second-order reaction model and thermodynamically it was spontaneous at lower temperature and exothermic in nature. The metal ions loaded adsorbent was also regenerated and reused for further adsorption of $\operatorname{Cr}($ III) ions from chrome-tanning effluents.

Keywords: Adoption mechanism; Adsorption capacity; Chromium(III); Tannery effluent; Regeneration

\section{Highlights}

- Preparation of graphene oxide (GO) from commercial graphite powder following modified Hummer's method

- Characterization of prepared GO by various instrumental analyses
- Adsorption of trivalent chromium from harmful chrome-tanning effluent is faster and higher than other adsorbents

- Provide a prominent adsorbent material for efficient treatment of tannery effluent 


\section{Introduction}

Tanneries are the major users of trivalent chromium $\left[\mathrm{Cr}(\mathrm{OH}) \mathrm{SO}_{4}\right.$ salt] after the alloy and metal finishing industry. Generally, $90 \%$ of the tanneries carry out the chrome tanning process for leather tanning due to excellent hydrothermal stability and some other unique properties like the smoothness of grain, uniform elasticity, and resistance to atmospheric conditions, etc $[1,2]$. During chrome-tanning, only $60 \%$ of the applied chrome salts are bound with the proteinous fibre (collagen) and the rest is disposed of with wastewaters ranging from 2656 to $5420 \mathrm{mg} / \mathrm{L}$ which is 1000 times higher than its threshold limit [3]. Unlike carcinogenic hexavalent chromium, Cr(III) is reported as less hazardous and noncorrosive, however, it also can cause several venomous health hazards, e.g. skin allergy, inflammation, nausea, DNA structure deformation, metabolic malfunction during prolonged exposure [4]. Therefore, the proper treatment of chrome-loaded tannery effluents should be required before discharging them into the environment.

Several techniques like precipitation, ion exchange, membrane filtration, ozonization, photocatalytic degradation, bioremediation, chemical coagulation, and electrochemical oxidation, etc. have been reported for the treatment of $\mathrm{Cr}$ (III)-loaded tannery effluents [5]. Adsorption is preferable for its remarkable removal efficiency of wideranged chemicals, inexpensiveness, and generating fewer secondary pollutant/sludge [6]. Activated carbon, zeolites, nanomagnetic materials are some popular adsorbents used for the remediation of hazardous pollutants from wastewaters [7]. However, owing to the high price of available adsorbents, selective adsorbent for the removal of a particular pollutant, and not as much regeneration capability of some adsorbents, the researchers are nowadays looking for advanced and efficient adsorbent materials [8]. Scientific reports have shown that biomass-based materials produced from various agricultural and household activities are used as adsorbents for their low cost, easy availability, and noticeable adsorption capacity towards metals and metals [9]. However, none of these adsorbents has shown proficient metal adsorption capacity.

In this context, nanomaterials can become prominent adsorbents to eliminate $\mathrm{Cr}$ (III) from chrome tanning effluents. Nanomaterials possess a huge surface area and stabilize chemical configuration and surface charge, which have indicated their superiority for metal removal [10]. Recently, graphene oxide (GO) has been of interest as an adsorbent to remove contaminants from wastewaters. As compared to other adsorbent materials, GO possess an extremely broad surface area $\left(2630 \mathrm{~m}^{2} / \mathrm{g}\right)$, and the manifestation of various functional groups viz. hydroxyl, epoxy, and carboxylic groups facilitate uncompromising adsorption capacity to contaminants $[7,11]$. Consequently, graphene oxide and its derivatives has become a centre of attraction in the research field of water purification [12]. Therefore, the research explores the suitability to use graphene oxide as an adsorbent to adsorb $\mathrm{Cr}$ (III) from harmful effluent released after chrome-tanning. Additionally, the optimization of the sorption method, and evaluating its equilibrium, kinetics and thermodynamic studies are performed. The adsorption rates are evaluated with pseudo-first-order and pseudosecond-order equations. The thermodynamic parameters such as standard enthalpy $(\Delta \mathrm{H})$, Gibbs free energy $(\Delta \mathrm{G})$, and system's entropy $(\Delta S)$ are measured by linearized Van't Hoff equations.

\section{Experimental}

\section{Materials}

Graphite powder (99.5 \%, Merck, India), Hydrogen peroxide (30\%, Merck India), Sulphuric acid (98\%, Active Fine Chemicals, Bangladesh), Nitric acid (65\%, Active Fine Chemicals, Bangladesh), Potassium permanganate (97\%, Merck, India), Sodium nitrate (Uni-chem, China) and hydrochloric acid (37\%, RCI Labscan, Thailand) were purchased for the synthesis of Graphene oxide. Chromium sulphate $\left(\mathrm{Cr}_{2}\left(\mathrm{SO}_{4}\right)_{3} \cdot 6 \mathrm{H}_{2} \mathrm{O}\right.$, Qualikems, India) were used for preparing a standard solution of chromium(III). All chemicals were of analytical grade and used as received.

\section{Graphene Oxide Synthesis}

G0 was prepared by modified Hummers' method [13]. To prepare GO, graphite powder ( $3.0 \mathrm{~g}$ ) was added to a mixture of concentrated $\mathrm{H}_{2} \mathrm{SO}_{4}$ and concentrated $\mathrm{HNO}_{3}$ (3:1 ratio, 75 $\mathrm{ml}$ ) in a round bottom flask with vigorous stirring to form a homogeneous suspension in a water bath. Then $\mathrm{KMnO}_{4}$ $(9.0 \mathrm{~g})$ followed by $\mathrm{NaNO}_{3}(1.5 \mathrm{~g})$ was added slowly to the flask and stirred for 2 hours. It was further stirred overnight and a thick paste was obtained. Then deionized water (120 $\mathrm{ml}$ ) was added to it and stirred for 4 hours in an oil bath at $35^{\circ} \mathrm{C}$. A deep brown reaction mixture was produced, which was washed with deionized water $(420 \mathrm{ml})$ followed by the addition of $30 \% \mathrm{H}_{2} \mathrm{O}_{2}(20 \mathrm{ml})$ to afford a bright yellow mixture. Finally, $5 \% \mathrm{HCl}(200 \mathrm{ml})$ was added to remove $\mathrm{Mn}^{2+}$ ions from the prepared graphene oxide and washed with deionized water several times until the $\mathrm{pH}$ of the solution was 7.0. Centrifugation was used to accelerate the neutralization process. A schematic diagram of GO synthesis is illustrated in Figure 1. 


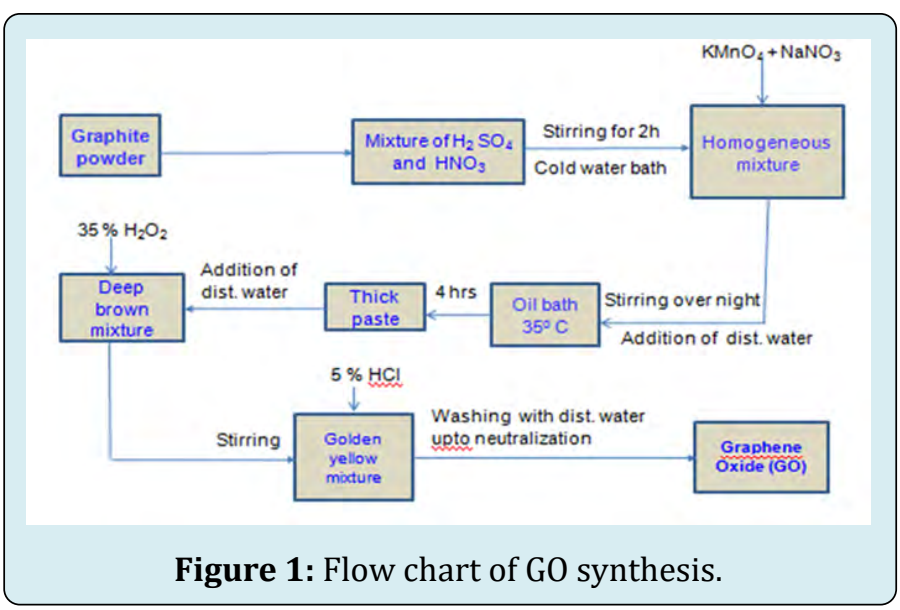

\section{Wastewater Collection}

An adequate quantity of chrome-containing tannery wastewater was collected in a sealed airtight plastic bottle from the discharge point of Reliance Tannery Limited, Savar, Dhaka following Pearson, et al. method [14]. The collected wastewater sample was filtered with Whatman No. 41 filter paper to remove suspended particles and the filtrate was stored for metal analysis at $4{ }^{\circ} \mathrm{C}$ to prevent hydrolysis.

\section{Adsorbent Characterization}

The prepared GO sample was further subjected to various instrumental analyses to assess the characteristics of the adsorbent. The chemical nature and surface pattern of the adsorbent was identified by Fourier transform infrared spectroscopy (FTIR) and x-ray diffraction (XRD) analysis. The morphological characteristics of GO were evaluated by Field emission scanning electron microscopy (FESEM). The ionic nature of the GO surface was studied by measuring the zeta potential charge (ZPC) through Zeta potential Analyzer (Nano-ZS ZEN 3600).

\section{Batch Tests and Metal Analysis}

Batch experiments were conducted to investigate the role of different functional parameters (viz. $\mathrm{pH}$, adsorbent dose, contact time, and initial concentration of chromium ions) for optimizing the adsorption process. The residual concentration of metal ions in the treated wastewater sample was measured by an Atomic absorption spectrophotometer (AAS). The metal removal rate and adsorption capacity of the adsorbent were calculated as followed:

$$
\begin{gathered}
\text { Adsorption capacity at time } \mathrm{t}, q_{t}=\frac{\left(c_{o}-c_{t}\right) \times v}{w} \\
\text { \% of Removal }=\frac{\left(c_{o}-c_{e}\right)}{c_{e}} \times 100 \text { (2) }
\end{gathered}
$$

$$
\text { Adsorption capacity at equilibrium, } q_{e}=\frac{\left(c_{o}-c_{e}\right) \times v}{w}
$$

where, $\mathrm{Co}=$ initial $\mathrm{Cr}$ (III) concentration of solution $(\mathrm{mg} / \mathrm{L})$, $\mathrm{C}_{\mathrm{t}}=$ concentration of $\mathrm{Cr}(\mathrm{III})$ in solution at time $\mathrm{t}(\mathrm{mg} / \mathrm{L}), \mathrm{C}_{\mathrm{e}}=$ concentration of $\mathrm{Cr}(\mathrm{III})$ in solution at equilibrium (mg/L), $\mathrm{V}=$ volume of the solution (L), and $\mathrm{w}=$ mass of the adsorbent $(\mathrm{g})$.

\section{Results and Discussion}

\section{Characterization of Prepared Adsorbent}

XRD Analysis: The x-ray diffraction (XRD) pattern of the synthesized GO is showed in Figure 2 that depicted a broad peak at $2 \boldsymbol{\theta}=10.399^{\circ}$ corresponding to an interlayer spacing of $8.5 \AA$, which is consistent with the literature value of $2 \boldsymbol{\theta}=$ $11.4^{\circ}$ and $d$-spacing $=7.8 \AA$ [15].

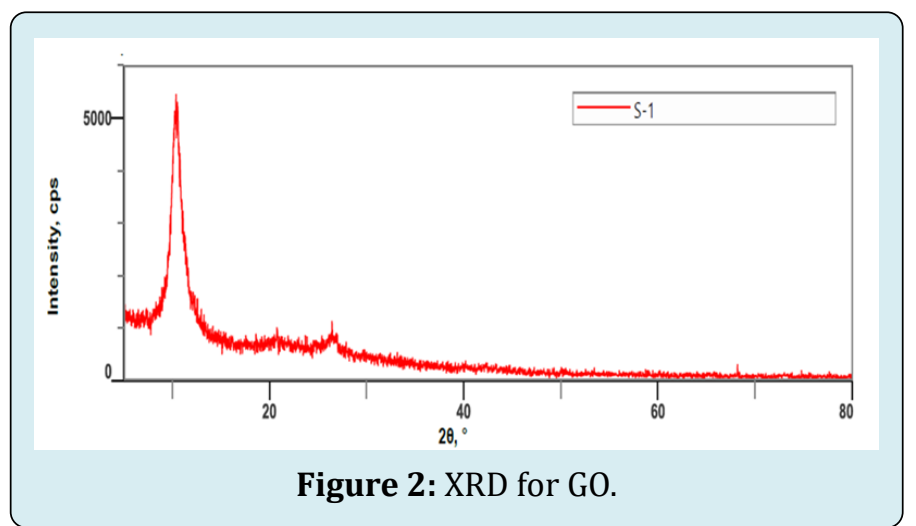

Microscopic Analysis: The morphology of the GO samples was assessed by FESEM. Figure 3 shows the SEM images of GO at 20,000 X and 10,000 X magnification. The working distance is about $6.6 \mathrm{~mm}$ at high vacuum mode with $5.0 \mathrm{kV}$. The image has shown fluffy, randomly aggregated and wrinkled sheets with a wide-ranged orientation of hierarchical pores that play the major roles in adsorbing metal ions [16]. This fluffiness and wrinkles in the GO are ensued due to oxidation and layer separation. Tan, et al. observed the same result in the SEM structure of their synthesized graphene oxide membrane which was used for the adsorption of some selected heavy metal ions from an aqueous solution [17].

Besides, the FESEM monographs showed a uniform surface after $\operatorname{Cr}(\mathrm{III})$ adsorption due to the binding of metal ions on the activated sites of the pores present on the GO surface (Figure 3(b)). A similar phenomenon has been reported by White et al. during copper $\left(\mathrm{Cu}^{2+}\right)$ adsorption onto graphene oxide (GO) and functionalized GO nanoparticles [18]. 


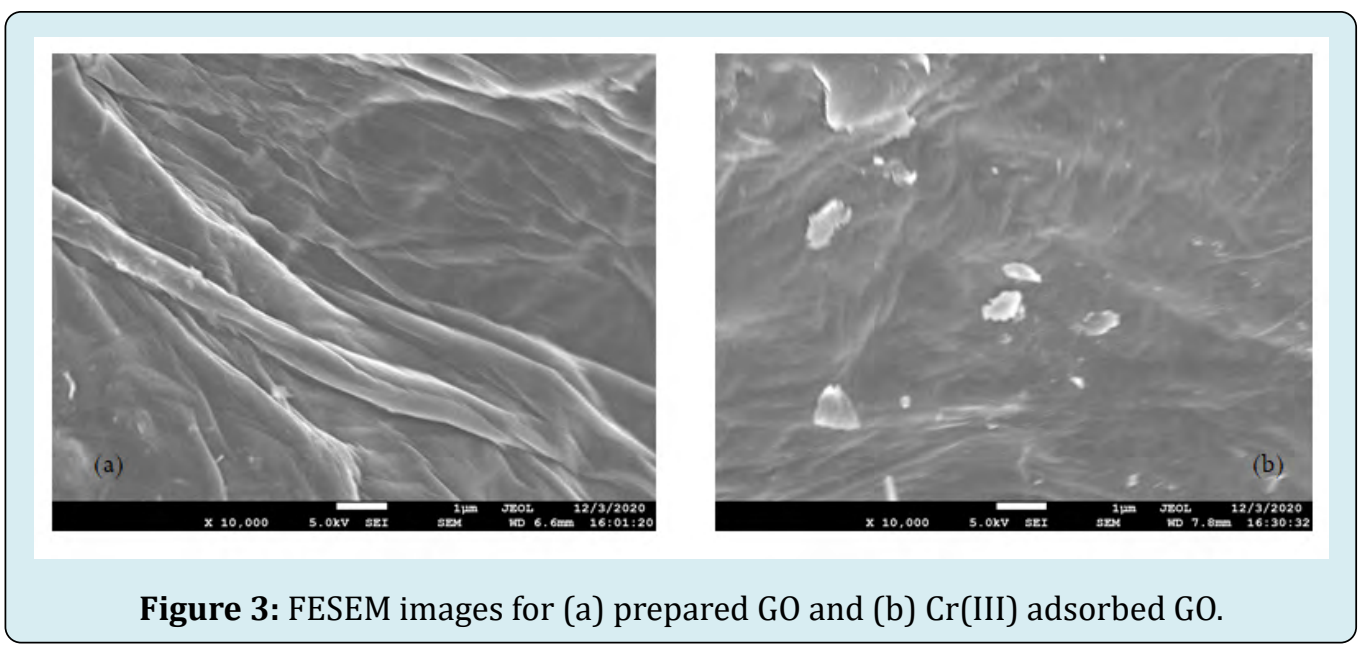

Spectral Analysis: The FT-IR spectra of graphene oxide showed in Figure 4, where some distinguished absorption peaks at different wavenumbers in the infrared region indicated the existence of various functional groups on the surface. It is observed that a strong and broad $\mathrm{O}-\mathrm{H}$ stretching vibration band at $3414 \mathrm{~cm}^{-1}$ because of extensive oxidation, $\mathrm{C}-\mathrm{H}$ stretching vibration at $2989 \mathrm{~cm}^{-1}, \mathrm{C}=0$ stretching vibration band of the carboxylic group at $1732 \mathrm{~cm}^{-1}$, aromatic $\mathrm{C}=\mathrm{C}$ stretching band at $1519 \mathrm{~cm}^{-1}$, symmetric $\mathrm{C}-\mathrm{O}$ stretching in the C-O-C group at $1209 \mathrm{~cm}^{-1}$ and the $\mathrm{C}-0$ (epoxy) band at $964 \mathrm{~cm}^{-1}$. The FT-IR spectra of graphene oxide was in a full agreement with the previous studies $[19,20]$.

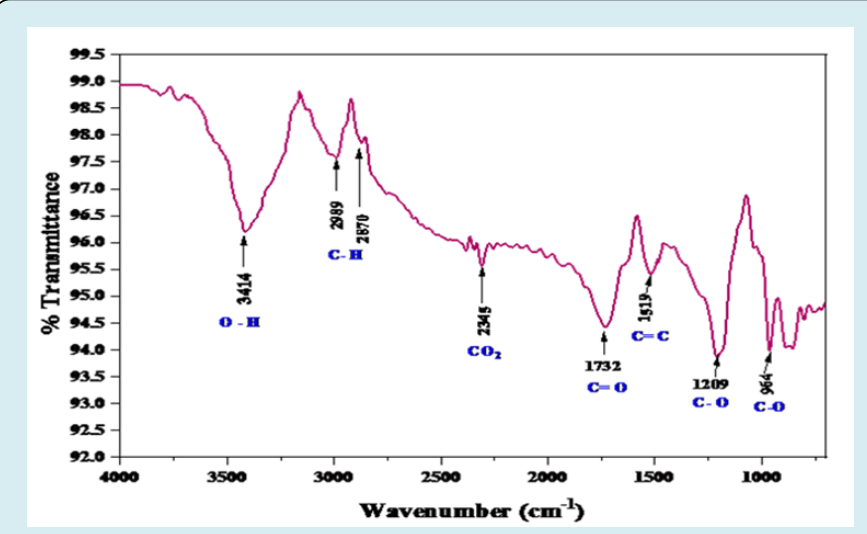

Figure 4: FT-IR spectrum for prepared GO.

\section{Effect of Operational Parameters on $\operatorname{Cr}$ (III) Adsorption Capacity of GO}

Effect of pH: To study the pH effect on the adsorption process, $20 \mathrm{ml}$ trivalent chromium salt solution of known concentration $(245.5 \mathrm{ppm})$ was taken in a series of conical flasks and treated with GO $(0.039 \mathrm{~g})$ at different $\mathrm{pH}$ range (25). The mixture was agitated in an orbital shaker at $150 \mathrm{rpm}$ for 2 hours at ambient temperature. The results revealed that the adsorption of $\mathrm{Cr}$ (III) onto the GO surface was maximum at $\mathrm{pH}$ 4.0. The carboxyl groups of GO is deprotonated and becomes negatively charged at $\mathrm{pH}$ higher than the ZPC (Figure 5a). The sorption capacity of GO is increased with an increased $\mathrm{pH}$. In an aqueous medium, trivalent chromium exists as $\mathrm{Cr}(\mathrm{III}), \mathrm{Cr}(\mathrm{OH})_{2}\left(\mathrm{H} 2 \mathrm{O}_{4}{ }_{4}^{+}, \mathrm{Cr}(\mathrm{OH})(\mathrm{H} 2 \mathrm{O})_{5}{ }^{2+}\right.$, or $\mathrm{Cr}(\mathrm{H} 2 \mathrm{O})_{6}{ }^{3+}$. Therefore, the GO surface starts to deprotonate as the $\mathrm{pH}$ increased and crosses the ZPC (Figure 5b), which brings a positive impact on the adsorption of $\operatorname{Cr}($ III) by creating a strong attraction force between cationic $\mathrm{Cr}$ (III) species and deprotonated GO [21]. However, the chromium is precipitated from an aqueous solution as $\mathrm{Cr}(\mathrm{OH})_{3}$ at higher $\mathrm{pH}(>6)$ due to an increase in its basicity and consequently, the study was not conducted at a higher $\mathrm{pH}$ range [22].

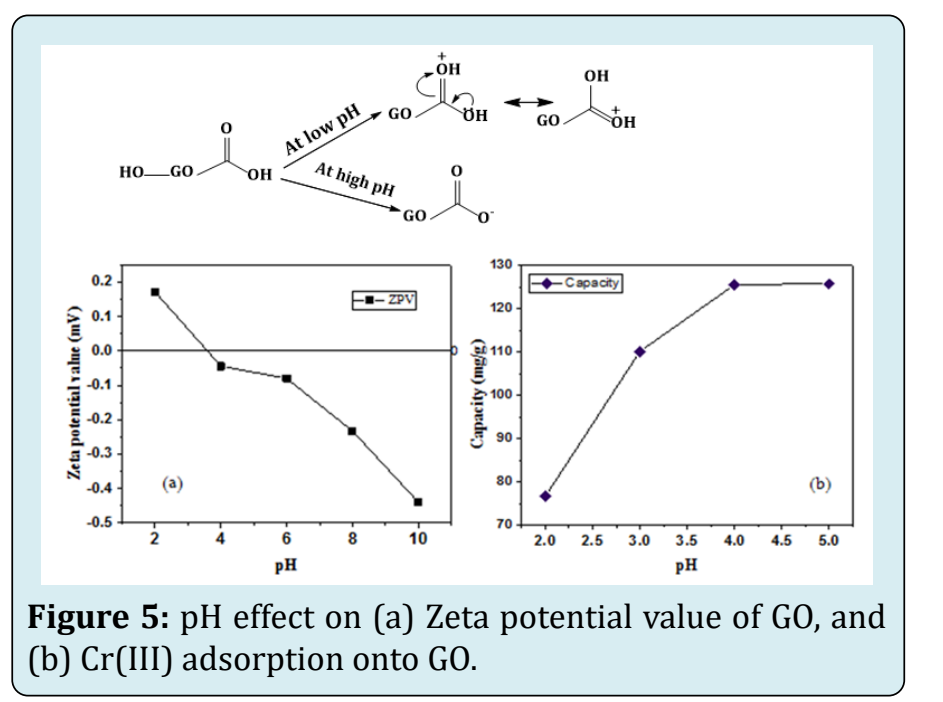

Effect of Adsorbent Dosage: A series of conical flasks in an orbital shaker using $10 \mathrm{ml}$ standard chromium salt solution $(245.5 \mathrm{ppm})$ was treated with different doses of GO $(0.25,0.5,1.0,1.5$, and $2.0 \mathrm{~g} / \mathrm{L})$ under optimum $\mathrm{pH}(4)$ for dose optimization. The experimental results revealed that the removal efficiency was increased with an increase in adsorbent dosages and the optimum dose was $0.6 \mathrm{~g} / \mathrm{L}$ 
(Figure 6). Usually, the number of active sites increases with the increase of adsorbent doses that yields higher surface area resulting in access to the metal ions to get interacted with the active sites of the adsorbent [23]. Similar results were obtained by Qiu, et al. in their research work on $\mathrm{Cr}$ (III) removal using sludge-derived biochar with supported nanosized zero-valent iron [24]. However, the sorption capacity reduces with an augmentation of the adsorbent amount. At a higher dose, it might cause aggregation of the adsorbent which attributes to the unsaturation of many active sites and hence most of the sites remain unreacted with the adsorbate [25].

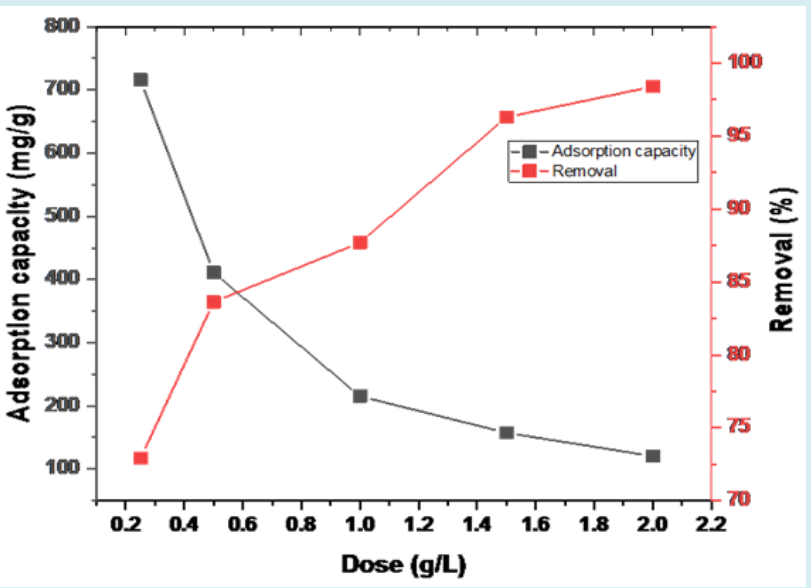

Figure 6: Effect of adsorbent dose on $\mathrm{Cr}$ (III) adsorption onto GO.

Effect of Contact Time and Metal Concentration: The batch experiments were conducted to determine the effects of contact time and initial Cr(III) concentration on adsorption capacity of GO (Fig. 7). The experiments were carried out by treating $10 \mathrm{ml}$ chromium(III) salt solution of different concentration (104.22, 125.4, 174, and 198.57 $\mathrm{ppm})$ with a fixed adsorbent doses $(0.6 \mathrm{~g} / \mathrm{L})$ at optimum $\mathrm{pH}$ (4) for a predetermined time interval (0-120 minutes). As showed in Figure 7, the increment of metal adsorption took place at 20 minutes and no significant changes were observed in the adsorption process after increasing the contact time. Abshirini, et al. opined that the vacant active sites present on the adsorbent surface start to get occupied by the adsorbate over time that raises the sorption capacity and has no significant effect on it when equilibrium time is achieved [23].

The initial metal concentration in the solution is one of the most significant driving forces in the adsorption process. It provides a brief description of the relationship of mass transfer and mass balance between the solute's in a liquid phase (adsorbate) and solid phase (adsorbent) [26]. Based on the findings, it illustrated that the adsorption capacity is increased by increasing the initial chromium concentration. It occurs because, at a higher concentration of metals, the ratio of activated sites on the adsorbent surface is nearly equal that confirms higher metal uptake [27].

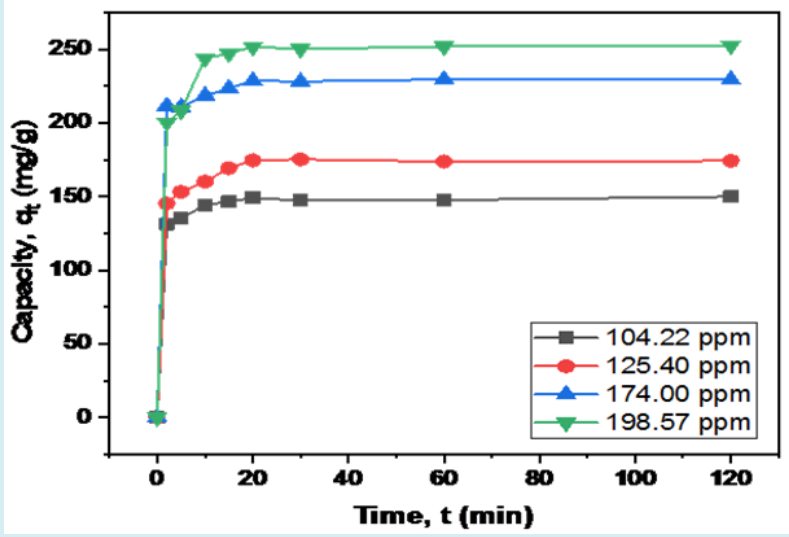

Figure 7: Effect of initial chrome concentration on metal adsorption onto GO over time.

\section{Isothermal Studies}

Isothermal studies focus on the sorption mechanism through establishing a relationship between adsorbate and adsorbent at equilibrium condition [28]. It also measures the maximum adsorption capacity of an adsorbent while adsorbing a particular material as adsorbate [29,30]. In this study, the sorption data were interpreted concerning two most widely used isotherm model, e.g. Langmuir and Freundlich isotherm (using their linearized form) to explain the equilibrium adsorption condition [31] using the following equations:

$$
\begin{gathered}
\frac{c_{e}}{q_{e}}=\frac{1}{q_{m} b}+\frac{1}{q_{m}} c_{e}(4) \\
R_{L}=\frac{1}{1+c_{m} b}(5) \\
\ln q_{e}=\ln k_{F}+\frac{1}{n} \ln c_{e}(6)
\end{gathered}
$$

where, $\mathrm{q}_{\mathrm{e}}=$ amount of adsorbed metal in per unit mass of adsorbent $(\mathrm{mg} / \mathrm{g}), \mathrm{C}_{\mathrm{e}}=$ equilibrium metal concentration $(\mathrm{mg} / \mathrm{L}), \mathrm{q}_{\mathrm{m}}=$ adsorption capacity $(\mathrm{mg} / \mathrm{g}), \mathrm{b}=$ Langmuir constant $(\mathrm{L} / \mathrm{mg}), \mathrm{R}_{\mathrm{L}}=$ separation factor.

The results are represented in the tabular form (Table 1) that denote the adsorption of $\mathrm{Cr}(\mathrm{III})$ onto GO surfaces follow both the Langmuir and Freundlich isotherm models indicating monolayer and multilayer adsorption of metal ions on GO with maximum adsorption capacity $\left(\mathrm{q}_{\max }\right) 366.3$ $\mathrm{mg} / \mathrm{g}$ (Figure 8). However, the isotherm constants and the $\mathrm{R}^{2}$ 
value (0.998) of both isotherm models were favourable and acceptable. Mondal and Chakraborty found similar results in their experiment [32].

\begin{tabular}{|c|c|c|c|}
\hline Langmuir Constants & Values & Freundlich constants & Values \\
\hline $\mathrm{qm}(\mathrm{mgg}-1)$ & 366.3 & $\mathrm{KF}$ & 45.02 \\
\hline $\mathrm{b}(\mathrm{L} \mathrm{mg}-1)$ & 0.046 & $\mathrm{n}$ & 2.232 \\
\hline $\mathrm{R}^{2}$ & 0.998 & $\mathrm{R}^{2}$ & 0.998 \\
\hline $\mathrm{RL}$ & 0.098 & & \\
\hline
\end{tabular}

Table 1 Isotherm constants for $\mathrm{Cr}(\mathrm{III})$ adsorption onto GO.
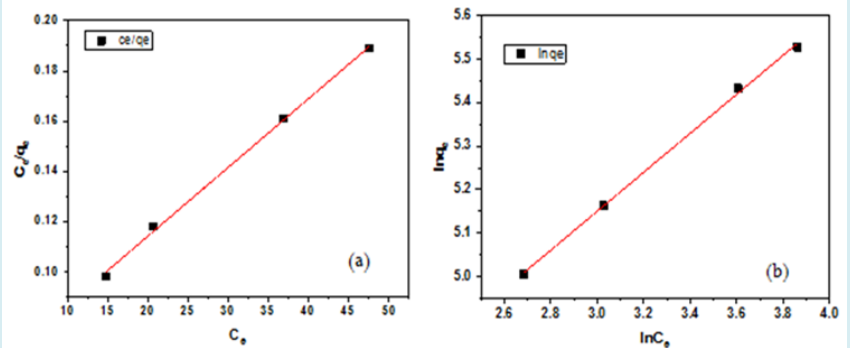

Figure 8: Isotherm models for $\mathrm{Cr}$ (III) adsorption on GO (a) Langmuir, and (b) Freundlich.

\section{Kinematic Studies}

The adsorption kinetics depicts the nature of adsorption onto the adsorbent surface. The two most popular kinetic models i.e. pseudo-first-order and pseudo-second-order reaction models were employed to understand the sorption of $\mathrm{Cr}$ (III) on GO. The following equations were applied to measure the kinetic parameters:

$$
\log \left(q_{e}-q_{t}\right)=\log q_{e}-\left(\frac{k_{1}}{2.303}\right) t(7)
$$

$$
\frac{t}{q_{t}}=\left(\frac{1}{k_{2} q_{e}^{2}}\right)+\left(\frac{1}{q_{e}}\right) t
$$

where $\mathrm{q}_{\mathrm{e}}=$ amount of solute adsorbed at equilibrium per unit weight of adsorbent $(\mathrm{mg} / \mathrm{g}), \mathrm{q}_{\mathrm{t}}=$ amount of solute adsorbed at any time $(\mathrm{mg} / \mathrm{g})$ and $\mathrm{k}_{1}=$ adsorption constant for pseudofirst-order reaction and $\mathrm{k}_{2}=$ adsorption constant for the pseudo-second-order reaction.

The findings of the experimental works fitted best with the pseudo-second-order reaction model with a regression coefficient value $\left(\mathrm{R}^{2}\right)$ of 0.999 (Table 2). A similar result was also observed in some previous studies based on graphene oxide and its derivatives for removing $\operatorname{Cr}($ III) ions from aqueous solutions [33-36]. This information also points towards the chemisorption nature of the adsorption process (Figure 9). Therefore, a strong attraction force has occurred between the anionic functional groups (hydroxyl, carboxylates, carbonyl, etc.) present in the adsorbent (GO) and metal ions that lead to forming covalent bonds and agitations in the electron systems of metal ions during the adsorption process [37].

\begin{tabular}{|c|c|c|c|c|c|}
\hline Kinetics Model & Parameters & $\mathbf{1 0 4 . 2 2} \mathbf{~ p p m}$ & $\mathbf{1 2 5 . 4 0} \mathbf{~ p m}$ & $\mathbf{1 7 4 . 0 0} \mathbf{~ p p m}$ & $\mathbf{1 9 8 . 5 7} \mathbf{~ p p m}$ \\
\hline Pseudo-first-order & $\mathrm{qe}^{*}\left(\mathrm{mg} \mathrm{g}^{-1}\right)$ & 25.64 & 41.11 & 24.66 & 88.31 \\
\hline & $\mathrm{k} 1$ & 0.149 & 0.127 & 0.0986 & 0.2089 \\
\hline & $\mathrm{R} 2$ & 0.974 & 0.953 & 0.931 & 0.941 \\
\hline & $\mathrm{qe}^{* *}\left(\mathrm{mgg}^{-1}\right)$ & 149.28 & 174.63 & 228.63 & 251.7 \\
\hline Pseudo-second-order & $\mathrm{qe}^{*}\left(\mathrm{mg} \mathrm{g}^{-1}\right)$ & 152.21 & 179.21 & 230.95 & 262.47 \\
\hline & $\mathrm{k} 2$ & 0.0135 & 0.0071 & 0.011 & 0.0042 \\
\hline & $\mathrm{R} 2$ & 0.999 & 0.998 & 0.999 & 0.998 \\
\hline & $\mathrm{qe}^{* *}\left(\mathrm{mg} \mathrm{g}^{-1}\right)$ & 149.28 & 174.63 & 228.67 & 251.7 \\
\hline
\end{tabular}

Table 2: Summary of adsorption kinetics.

${ }^{*}$ Theoretical, ${ }^{* *}$ Experimental 

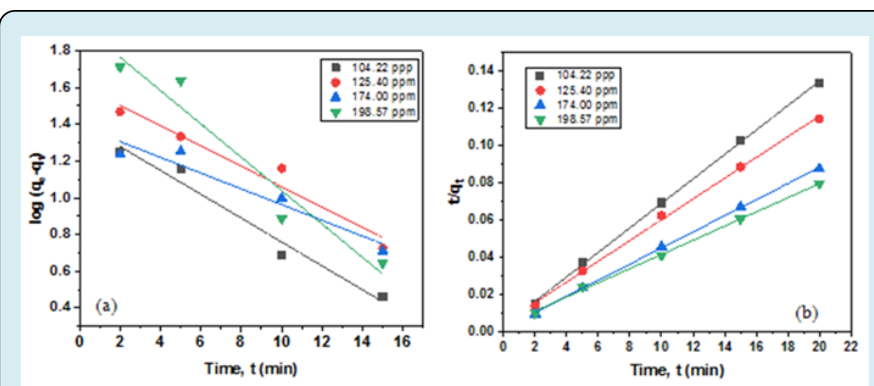

Figure 9: Kinetic models (a) pseudo-first-order and (b) pseudo-second-order reaction for $\mathrm{Cr}$ (III) adsorption on GO.

\section{Thermodynamics Study}

The thermodynamic study of an adsorption process ascertains its randomness and feasibility based on temperature [8] (Figure 10). The removal of $\mathrm{Cr}$ (III) by GO was evaluated under different temperature (293-338 K) intervals and the thermodynamic parameters such as standard enthalpy $(\Delta \mathrm{H})$, Gibbs free energy $(\Delta \mathrm{G})$, and system's entropy $(\Delta S)$ were measured by linearized Van't Hoff equations [38].

$$
\begin{gathered}
\Delta G^{o}=-R T \ln K_{d}(9) \\
\ln k_{d}=\frac{-\Delta H^{o}}{R T}+\frac{\Delta S^{o}}{R} \\
\Delta S^{o}=-\frac{\Delta G^{0}-\Delta H^{o}}{T}
\end{gathered}
$$

The calculated results reveal that the sorption of metal ions reduces at a higher temperature. The enthalpy value indicated that the sorption process is exothermic and entropy-driven. Moreover, it is spontaneous at a lower temperature (Table 3).

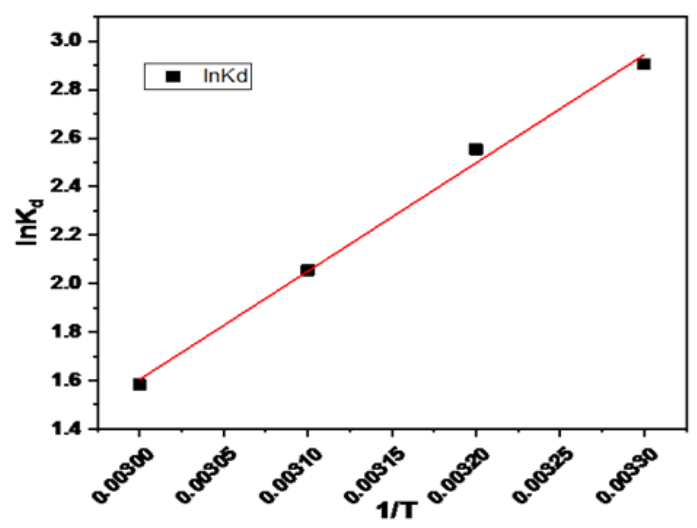

Figure: 10 Adsorption thermodynamics.

\begin{tabular}{|c|c|c|c|}
\hline $\mathbf{T}(\mathbf{K})$ & $\mathbf{\Delta G}(\mathbf{k J} / \mathbf{m o l e})$ & $\boldsymbol{\Delta H}(\mathbf{k J} / \mathbf{m o l e})$ & $\mathbf{\Delta S}(\mathbf{k J} / \mathbf{m o l e})$ \\
\hline 293 & -7.197 & -37.147 & -0.0981 \\
\hline 308 & -6.54 & & \\
\hline 323 & -5.433 & & \\
\hline 338 & -4.314 & & \\
\hline
\end{tabular}

Table 3: Thermodynamics parameters of chromium adsorption.

\section{Regeneration of GO}

To study the potential re-use of $\mathrm{Cr}$ (III) loaded GO was regenerated using $2 \% \mathrm{HCl}$ and reused for $\mathrm{Cr}$ (III) adsorption at optimum $\mathrm{pH}$, adsorbent dose and time. The results of regeneration studies showed that adsorption capacity slowly decreases from 150.85 to $142.87,118.23$ and $68.92 \mathrm{mg} / \mathrm{g}$ after recycle-1, recycle- 2 and recycle- 3 respectively (Figure 11) and revealed that regenerated GO can be reused for the removal of $\mathrm{Cr}(\mathrm{III})$ from the aqueous solution after further improvement.

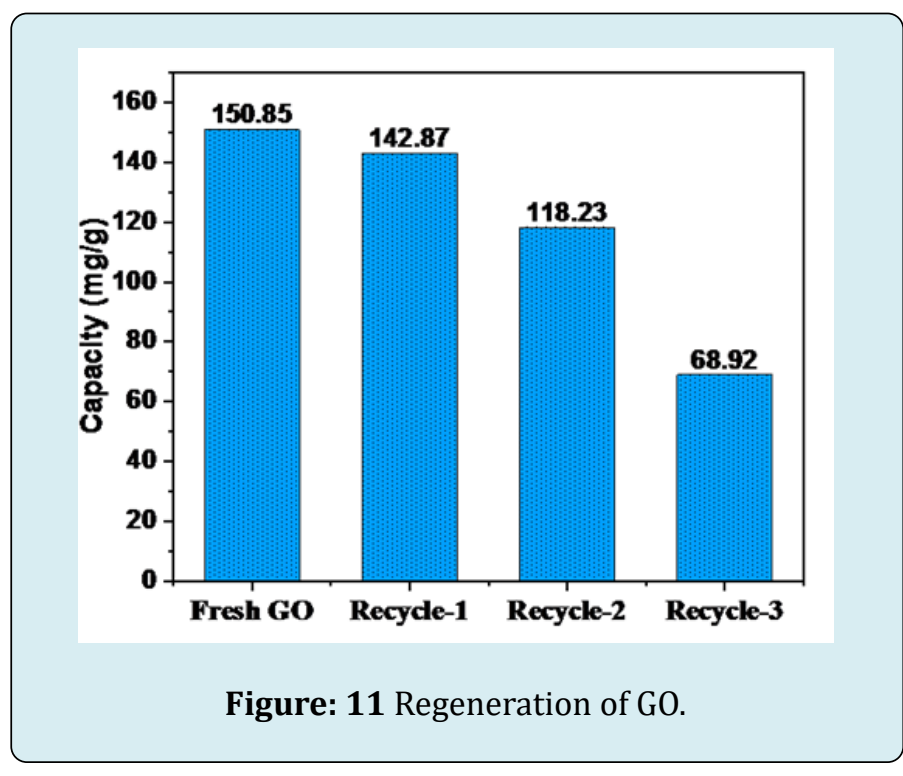

\section{Evaluation of Physicochemical Parameters}

Several physicochemical parameters of wastewater sample were measured before and after adsorption and the results are presented in a tabular form (Table 4) that expressed significant changes in the physicochemical parameters after the treatment of effluent samples with GO. It proves the proficient removal capacity of GO during wastewater treatment. 
Physical Science \& Biophysics Journal

\begin{tabular}{|c|c|c|c|c|}
\hline Parameters & Before Adsorption & After Adsorption & \% of Removal & ECR [39] \\
\hline Cr(III) concentration $(\mathrm{ppm})$ & 3477.5 & 1673.25 & 54.19 & 2 \\
\hline Adsorption Capacity $(\mathrm{mg} / \mathrm{g})$ & - & 180.43 & - & - \\
\hline $\mathrm{pH}$ & 4.1 & 5.3 & - & 9-Jun \\
\hline $\mathrm{TDS}(\mathrm{ppm})$ & 5135 & 1982 & 61.4 & 2100 \\
\hline $\mathrm{EC}(\mu \mathrm{S} / \mathrm{cm})$ & 10165 & 3967 & 60.97 & - \\
\hline $\mathrm{NaCl}(\%)$ & 17.6 & 6.8 & 61.36 & - \\
\hline BOD5 (ppm) & 4643 & 1953 & 57.93 & 100 \\
\hline COD $(\mathrm{ppm})$ & 12164 & 5424 & 55.41 & - \\
\hline
\end{tabular}

Table 4: Changes in physicochemical parameters of the tanning effluent after adsorption.

\section{Plausible Adsorption Mechanism of GO}

The adsorption mechanism deals with the interaction between oppositely ionized particles through different bond formations such as hydrogen bonding, electrostatic or $\pi-\pi$ interactions, Vander Waals forces, dipole-dipole induction, ion-exchange and so on. The surface chemistry and pore density/volume are the two topmost variables with significant influences during the sorption of a solute onto an adsorbent surface. At the optimum pH (4.0), graphene oxide possesses a negative surface charge and showed electrostatic interaction to the cationic metal ion. As Cr-ions usually form hexacoordinate complexes, the carboxylate groups containing GO form hexacoordinate complexes by capturing Cr(III) ions from the solution (Figure 12).

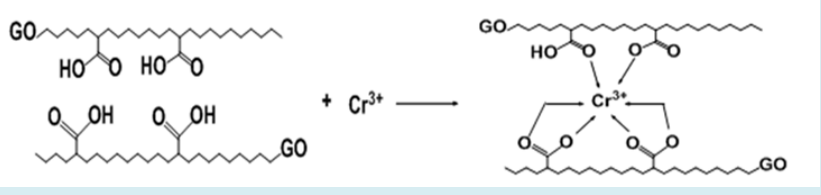

Figure 12: Adsorption mechanism of $\mathrm{Cr}(\mathrm{III})$ on GO.

\section{Effectiveness of GO as Adsorbent}

Recently, GO and its derivatives have gained much attention from researchers as prominent adsorbents for removing pollutants from water bodies. Therefore, the compatibility of GO on $\mathrm{Cr}$ (III) removal was compared with other adsorbents in Table 4 that showed remarkable metal uptake than most other adsorbents.

\begin{tabular}{|c|c|c|c|c|c|c|c|}
\hline Adsorbent name & $\mathbf{p H}$ & $\begin{array}{c}\text { Adsorbent } \\
\text { dose }\end{array}$ & $\begin{array}{c}\text { Initial Cr(III) } \\
\text { concentration }\end{array}$ & $\begin{array}{c}\text { Contact } \\
\text { time }\end{array}$ & $\begin{array}{c}\text { \% } \\
\text { Removal }\end{array}$ & $\begin{array}{c}\text { Adsorption } \\
\text { capacity (mg/g) }\end{array}$ & Reference \\
\hline Fish scale & 5 & $0.8 \mathrm{~g}$ & $150 \mathrm{mg} / \mathrm{L}$ & $90 \mathrm{~min}$. & 99.7518 & 18.3486 & {$[40]$} \\
\hline $\begin{array}{c}\text { GO/alginate hydrogel } \\
\text { membrane }\end{array}$ & 6 & - & $40 \mathrm{mg} / \mathrm{L}$ & $60 \mathrm{~min}$. & & 118.6 & {$[41]$} \\
\hline Activated carbon & 4 & & $200 \mathrm{mg} / \mathrm{L}$ & $\begin{array}{c}3-5 \\
\text { months }\end{array}$ & & & {$[42]$} \\
\hline Graphene oxide & 4 & $0.6 \mathrm{~g} / \mathrm{L}$ & $174 \mathrm{mg} / \mathrm{L}$ & $20 \mathrm{~min}$. & 98.77 & 366.3 & This work \\
\hline
\end{tabular}

Table 5: Comparison of GO with other adsorbents on $\mathrm{Cr}(\mathrm{III})$ adsorption.

\section{Conclusions}

Graphene oxide can be used as an advanced and costeffective adsorbent to eliminate $\mathrm{Cr}^{3+}$ ions from harmful tannery wastewaters. The results of batch experiments showed the highest metal removal (98.77\%) was achieved at pH 4 by treating a spent chrome-tanning sample of an initial concentration of $174 \mathrm{mg} / \mathrm{L}$ with $0.6 \mathrm{~g} / \mathrm{L} \mathrm{GO}$ for 20 minutes. The adsorption equilibrium of $\mathrm{Cr}$ (III) on GO was adequately described by both Langmuir and Freundlich isotherm models indicating a complex adsorption phenomenon (both monolayer and multilayer). Excellent adsorption capacity of $366 \mathrm{mg} / \mathrm{gm}$ was calculated from Langmuir isotherm. Additionally, sorption kinetics followed a pseudo-secondorder reaction mechanism, and thermodynamically it was spontaneous adsorption of metal ions from solution (liquid) to adsorbent site (solid) interphase at lower temperature and exothermic in nature. The adsorption capacity of $\mathrm{Cr}^{3+}$ onto GO was found higher than most other adsorbents. Thus, GO can be a potential candidate as an adsorbent for the removal of Cr(III) from chrome-tanning effluent. 


\section{Author Contributions}

Sobur Ahmed: Conceptualization, Methodology, Investigation, Writing- Original draft. Fatema-Tuj-Zohra: Writing- Introduction, Literature review, Software and Data formatting. Meem Muhtasim Mahdi: Methodology, Formal analysis, Data Collection, Writing- Original draft. Tasrina Rabia Choudhury: Visualization, Data analysis, WritingReview. Md. Zahangir Alam: Supervision, Resources, Writing -Methodology, Review and Editing. Md. Nurnabi: Resources, Supervision, Writing- Review, Editing and Finalizing. All authors have read and agreed to the published version of the manuscript.

\section{Acknowledgement}

The authors would like to thank the authorities of Department of Applied Chemistry \& Chemical Engineering and Institute of Leather Engineering and Technology (ILET), University of Dhaka and Atomic Energy Center, Bangladesh Atomic Energy Commission, Dhaka, Bangladesh for providing the lab facilities and testing supports.

\section{Conflict of interest}

The authors have no conflict of interest.

\section{Source of funding}

No research grant/sponsorship has been rewarded to conduct this research.

\section{References}

1. Ahmed S, Fatema-Tuj-Zohra, Khan MSH, Hashem MA (2017) Chromium from tannery waste in poultry feed: A potential cradle to transport human food chain. Cogent Environ Sci 3(1): 1312767.

2. Ozkan CK, Ozgunay H, Akat H (2019) Possible use of corn starch as tanning agent in leather industry: Controlled (gradual) degradation by $\mathrm{H}_{2} \mathrm{O}_{2}$. Int J Biol Macromol 122: 610-618.

3. Hashem MA, Hasan M, Momen MA, Payel S, Nur-ATomal MS (2020) Water hyacinth biochar for trivalent chromium adsorption from tannery wastewater. Environ Sustain Indic 5: 100022.

4. Achmad RT, Budiawan, Auerkari EI (2017) Effects of chromium on human body. Ann Res Rev Biol 17(2): 1-8.

5. Nur-E-Alam M, Mia MAS, Ahmad F, Rahman MM (2020) An overview of chromium removal techniques from tannery effluent. Appl Water Sci 10: 1-22.
6. Priastomo Y, Setiawan HR, Kurniawan YS, Ohto K (2020) Simultaneous removal of lead (II), chromium (III), and copper (II) heavy metal ions through an adsorption process using C-phenylcalix [4] pyrogallolarene material. J Environ Chem Eng 8(4): 103971.

7. Wijaya R, Andersan G, Santoso SP, Irawaty W (2020) Green reduction of graphene oxide using kaffir lime peel extract (Citrus hystrix) and its application as adsorbent for methylene blue. Sci Rep 10: 1-9.

8. Raghav S, Kumar D (2018) Adsorption equilibrium, kinetics, and thermodynamic studies of fluoride adsorbed by tetrametallic oxide adsorbent. J Chem Eng Data 63(5): 1682-1697.

9. Ghosh S, Mitra D (2018) Urban Ecology, Water Quality and Climate Change. Springer, pp: 267-274.

10. Mitra S, Sarkar A, Sen S (2017) Removal of chromium from industrial effluents using nanotechnology: a review. Nanotechnol. Environ Eng 2: 1-14.

11. Yang X, Zhou T, Ren B, Hursthouse A, Zhang Y (2018) Removal of $\mathrm{Mn}$ (II) by sodium alginate/graphene oxide composite double-network hydrogel beads from aqueous solutions. Sci Rep 8: 1-16.

12. Abu-Nada A, McKay G, Abdala A (2020) Recent advances in applications of hybrid graphene materials for metals removal from wastewater. Nanomaterials 10(3): 595.

13. Zaaba N, Foo K, Hashim U, Tan S, Liu WW, et al. (2017) Synthesis of graphene oxide using modified hummers method: solvent influence. Proc Eng 184: 469-477.

14. Pearson H, Mara D, Bartone C (1987) Guidelines for the minimum evaluation of the performance of full-scale waste stabilization pond systems. Water Res 21(9): 1067-1075.

15. Iqbal MZ, Abdala AA (2013) Thermally reduced graphene: synthesis, characterization and dye removal applications. RSC Adv 3(46): 24455-24464.

16. Wang J, Chen B (2015) Adsorption and coadsorption of organic pollutants and a heavy metal by graphene oxide and reduced graphene materials. Chem Eng J 281: 379388.

17. Tan P, Sun J, Hu Y, Fang Z, Bi Q, et al. (2015) Adsorption of $\mathrm{Cu}^{2+}, \mathrm{Cd}^{2+}$ and $\mathrm{Ni}^{2+}$ from aqueous single metal solutions on graphene oxide membranes. J Hazard Mater 297: 251-260.

18. White RL, White CM, Turgut H, Massoud A, Tian ZR (2018) Comparative studies on copper adsorption by graphene oxide and functionalized graphene oxide nanoparticles. J Taiwan Inst Chem Eng 85: 18-28. 
19. Mahmudunnabi DM, Alam MZ, Nurnabi M (2020) Removal of TURQUOISE GN from aqueous solution using graphene oxide. Desalin Water Treat 174: 389-399.

20. Valencia C, Valencia CH, Zuluaga F, Valencia ME, Mina JH, et al. (2018) Synthesis and Application of Scaffolds of Chitosan-Graphene Oxide by the Freeze-Drying Method for Tissue Regeneration. Molecules 23(10): 2651.

21. Bedemo A, Chandravanshi BS, Zewge F (2016) Removal of trivalent chromium from aqueous solution using aluminum oxide hydroxide. SpringerPlus 5: 1-11.

22. Santos VCGD, Salvado AdPA, Dragunski DC, Peraro DNC, Tarley CRT, et al. (2012) Highly improved chromium (III) uptake capacity in modified sugarcane bagasse using different chemical treatments. Quím Nova 35: 16061611.

23. Abshirini Y, Foroutan R, Esmaeili H (2019) Cr (VI) removal from aqueous solution using activated carbon prepared from Ziziphus Spina-Christi leaf. Mater Res Exp 6(4): 045607.

24. Qiu Y, Zhang Q, Gao B, Li M, Fan Z, et al. (2020) Removal mechanisms of $\mathrm{Cr}$ (VI) and $\mathrm{Cr}$ (III) by biochar supported nanosized zero-valent iron: Synergy of adsorption, reduction and transformation. Environ Pollut 265(P B): 115018.

25. Sahu O, Singh N (2019) The impact and prospects of green chemistry for textile technology. $1^{\text {st }}$ (Edn.), Elsevier, pp: 367-416.

26. Patel H (2019) Fixed-bed column adsorption study: a comprehensive review. Appl Water Sci 9: 1-17.

27. Bohli T, Ouederni A, Villaescusa I (2017) Simultaneous adsorption behavior of heavy metals onto microporous olive stones activated carbon: analysis of metal interactions. Euro-Meditt J Environ Integ 2: 1-15.

28. Vu H, Frydl T, Dvorak P, Selucka J, Starkova P (2017) Energy Technology. Springer, pp: 229-238.

29. Aranda-García E, Cristiani-Urbina E (2020) Hexavalent chromium removal and total chromium biosorption from aqueous solution by Quercus crassipes acorn shell in a continuous up-flow fixed-bed column: Influencing parameters, kinetics, and mechanism. Plos one 15: e0227953.

30. Lopez-Nuñez PV, Aranda-García E, Cristiani-Urbina MdC, Morales-Barrera L, Cristiani-Urbina E (2014) Removal of hexavalent and total chromium from aqueous solutions by plum (P. domestica L.) tree bark. Environ. Eng Manage J 13(8): 1927-1938.

31. Jeppu GP, Clement TP (2012) A modified Langmuir-
Freundlich isotherm model for simulating $\mathrm{pH}$-dependent adsorption effects. J Contamin Hydrol 129-130: 46-53.

32. Mondal NK, Chakraborty (2020) Adsorption of Cr (VI) from aqueous solution on graphene oxide (GO) prepared from graphite: equilibrium, kinetic and thermodynamic studies. Appl Water Sci 10: 1-10.

33. Li H, Chi Z, Li J (2014) Covalent bonding synthesis of magnetic graphene oxide nanocomposites for $\mathrm{Cr}$ (III) removal. Desalin Water Treat 52(10-12): 1937-1946.

34. Lingamdinne LP, Kim IS, Ha JH, Chang YY, Koduru JR, et al. (2017) Enhanced adsorption removal of $\mathrm{Pb}$ (II) and Cr (III) by using nickel ferrite-reduced graphene oxide nanocomposite. Metals 7(6): 225.

35. Lingamdinne LP, Koduru JR, Choi YL, Chang YY, Yang JK (2016) Studies on removal of $\mathrm{Pb}$ (II) and $\mathrm{Cr}$ (III) using graphene oxide based inverse spinel nickel ferrite nanocomposite as sorbent. Hydrometallurgy 165(P 1): 64-72.

36. Yang S, Li L, Pei Z, Li C, Lv J, et al. (2014) Adsorption kinetics, isotherms and thermodynamics of $\mathrm{Cr}$ (III) on graphene oxide. Colloids Surf. A: Physicochem Eng Asp 457: 100-106.

37. Yang X, Wan Y, Zheng Y, He F, Yu Z, et al. (2019) Surface functional groups of carbon-based adsorbents and their roles in the removal of heavy metals from aqueous solutions: a critical review. Chem Eng J 366: 608-621.

38. Lima EC, Gomes AA, Tran HN (2020) Comparison of the nonlinear and linear forms of the van't Hoff equation for calculation of adsorption thermodynamic parameters $(\Delta$ $\mathrm{S}^{\circ}$ and $\Delta \mathrm{H}^{\circ}$ ). J Mol Liq 311: 113315.

39. Environmental Conservation Rules (ECR) (1997) Ministry of Environment and Forest (MoEF). Government of People's Republic of Bangladesh, pp: 221-222.

40. Teshale F, Karthikeyan R, Sahu O (2020) Synthesized bioadsorbent from fish scale for chromium (III) removal. Micron 130: 102817.

41. Bai C, Wang L, Zhu Z (2020) Adsorption of Cr (III) and $\mathrm{Pb}$ (II) by graphene oxide/alginate hydrogel membrane: Characterization, adsorption kinetics, isotherm and thermodynamics studies. Int J Biol Macromol 147: 898910.

42. Lyubchik SB, Perepichka II, Galushko OL, Lyubchik AI, Lygina ES, et al. (2005) Optimization of the conditions for the $\mathrm{Cr}$ (III) adsorption on activated carbon. Adsorption 11: 581-593. 